\title{
Laboreal
}

Volume 15 №2 | 2019

Varia

\section{Bélgica, 24 de dezembro de 1963: o reconhecimento da silicose como doença profissional}

\section{Eric Geerkens}

\section{(2) OpenEdition}

1 Journals

\section{Edição electrónica}

URL: http://journals.openedition.org/laboreal/15306

DOI: 10.4000/laboreal. 15306

ISSN: 1646-5237

\section{Editora}

Universidade do Porto

\section{Refêrencia eletrónica}

Eric Geerkens, «Bélgica, 24 de dezembro de 1963: o reconhecimento da silicose como doença profissional », Laboreal [Online], Volume 15 №2 | 2019, posto online no dia 01 dezembro 2019, consultado o 14 setembro 2020. URL : http://journals.openedition.org/laboreal/15306

Este documento foi criado de forma automática no dia 14 setembro 2020.

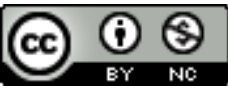

Laboreal está licenciado com uma Licença Creative Commons - Atribuição-NãoComercial 4.0 Internacional. 


\title{
Bélgica, 24 de dezembro de 1963: o reconhecimento da silicose como doença profissional
}

\author{
Eric Geerkens
}

1 A lei de 24 de dezembro de 1963 põe termo a quase quatro décadas em que a Bélgica se destacou pelo seu sistema de indemnização das doenças profissionais. Esta lei vai modificar profundamente uma outra de 1927, criticada desde a sua aprovação, e incluir a indemnização da silicose dos mineiros, até então excluída da lei para ser contemplada no quadro de uma reforma antecipada por invalidez.

\section{Características e fragilidades da lei de 24 de julho de 1927 relativa à indemnização dos danos causados por doenças profissionais}

2 Tal como em inúmeras economias industrializadas, a indemnização por doenças profissionais surge posteriormente à dos acidentes de trabalho, devido à especial dificuldade da atribuição da responsabilidade. A lei belga de 1927, "uma das poucas leis que obtiveram unanimidade no Parlamento", tem um carácter meramente transacional e não deve ser de modo nenhum considerada uma "grande vitória" dos trabalhadores, apesar de as organizações sindicais terem conseguido que a entidade patronal fosse reconhecida como a única responsável por essas doenças profissionais e, por isso mesmo, a única a financiar a indemnização.

3 O reduzido âmbito de aplicação da lei (as únicas três doenças contempladas são as incluídas na Convenção Internacional do Trabalho $n^{\circ} 18$ de 1925) foi, em teoria, atenuado pela perspetiva de um alargamento da lista de doenças objeto de indemnização de que uma seç̧ão do Fundo de Previdência das Vítimas de Doenças Profissionais ficou especificamente incumbida, a saber, a Comissão Técnica. No entanto, a entidade patronal mantém aí uma garantia substancial na aprovação das decisões 
dessa comissão técnica. A inclusão de uma doença na lista exigia maiorias específicas : ou o voto dos três médicos que integram a Comissão ou o voto de representantes de cada um dos grupos. Tendo em conta que a composição dessa comissão incluía sempre um médico de empresa, o patronato dispunha assim de um direito de veto, caso fosse imposta uma disciplina de voto. Como a lei belga se baseia numa lista dupla, as doenças consideradas profissionais e os sectores que causam exposição, o veto da Comissão Técnica podia incidir em qualquer destas vertentes.

4 A lei observava o princípio da responsabilidade coletiva por sector causador da exposição, mas o patronato defendeu desde o início que "os grupos industriais responsáveis por suportar os encargos dos sinistros devem estar extremamente bem definidos", defendendo uma diferenciação entre subsectores causadores sempre que exequível, por exemplo, dentro da própria empresa, entre as diferentes atividades produtivas. Esta delimitação restritiva da responsabilidade deu imediatamente origem a dificuldades práticas na cobrança das contribuições, gerando uma grande heterogeneidade de escalões e problemas de financiamento no caso de o sector ser pequeno e de risco elevado. A um patronato com uma visão restritiva da atribuição da responsabilidade, os funcionários dirigentes do Fundo de Previdência contrapuseram uma forma de solidariedade que obrigava a que o pagamento das indemnizações fosse suportado por todo o patronato, o que vigorou desde 1941. Isto resultou, durante muito tempo, em protestos das empresas que se viam obrigadas a pagar mais do que os custos dos danos que causavam.

Dado que a responsabilidade das empresas causadoras de exposição ao risco assentava na declaração da respetiva entidade patronal, as constantes subdeclarações privaram o Fundo, sem meios de controlo adequados, de uma parte significativa das receitas que lhe eram devidas.

6 Com meios financeiros estruturalmente insuficientes, as indemnizações às vítimas acabam por ser em número reduzido: ao longo dos cerca de trinta e cinco anos de atividade, o Fundo só indemnizou 5174 vítimas das 13190 declaradas, ou seja, uma taxa média de aceitação de 39 \% durante todo esse período. A avaliação da invalidez também vai ser muito parca : entre 1930 e 1937, em $85 \%$ dos casos, fixou-se abaixo dos $50 \%$ de invalidez (Moldaver, 1939, p. 130).

7 A situação permanentemente deficitária do Fundo vai impedi-lo de continuar com uma política de prevenção assente em incentivos financeiros, ao ponto de a responsabilização coletiva por ramo levar a comportamentos oportunistas.

À vontade dos sindicatos de que fosse unicamente a entidade patronal a suportar os encargos das indemnizações das doenças profissionais, este sector respondeu que só aceitava pagar os custos das doenças profissionais pelas quais fosse o único responsável. Estas posições de princípio e as correspondentes implicações técnicas contribuíram para uma certa paralisação do Fundo, cuja reforma foi protelada pela decisão de não incluir nele a silicose dos mineiros e pela dificuldade de inverter essa situação. 


\section{0 acordo Delattre de 1937 para os trabalhadores mineiros}

9 No quadro da elaboração da lei de 1927, o patronato do sector mineiro do carvão foi o único que conseguiu fazer ouvir uma forte oposição e obteve que nem o nistagmo nem a ancilostomíase nem o enfisema pulmonar constassem da lista das doenças suscetíveis de indemnização.

10 Quando, em 1934, o Secretariado Internacional do Trabalho (BIT) propõe a inclusão da silicose na lista das doenças profissionais suscetíveis de indemnização[ $\left.{ }^{1}\right]$, as entidades patronais desse sector não pararam de tentar eximir as empresas mineiras do carvão da obrigação de indemnizar as patologias respiratórias dos mineiros como doenças profissionais. Chegaram até a financiar um grande estudo com o objetivo de provar a inexistência de silicose no sentido restrito que tinha sido aprovado numa conferência do Secretariado Internacional do Trabalho realizada em Joanesburgo em 1930. As greves de 1936 vão, no entanto, levantar de novo a questão da silicose na Comissão Técnica do Fundo de Previdência. O presidente desta comissão, pressentindo os obstáculos que a referência à silicose poderia levantar, propôs que não se utilizasse essa palavra, mas antes a categoria genérica de "pneumoconioses" que facilitava a inscrição na lista das doenças suscetíveis de indemnização. A probabilidade de inclusão das minas de carvão nos sectores originadores da pneumoconiose aumentava. E foi então que o patronato tirou da manga uma solução alternativa.

11 Concluiu-se um acordo entre a Federação patronal e o Ministro do Trabalho, ele próprio antigo presidente da principal central sindical de mineiros, que contemplava o direito a reforma antecipada por invalidez em caso de pneumoconiose, a ser financiada por um aumento das cotizações de trabalhadores e patrões. Esta decisão, transposta para a lei, permitiu nomeadamente, indemnizar um maior número de vítimas, cujas pensões foram revistas, mas sobretudo refinanciar o próprio Fundo Nacional de Pensões dos Trabalhadores Mineiros que tinha sido apanhado pelas medidas de racionalização que, para além de o terem privado das cotizações dos cerca de 50000 mineiros despedidos, levaram-no a incluir uma doença de proporções, na altura, desconhecidas: a pneumoconiose dos mineiros, mais conhecida na Bélgica por silicose (Geerkens, 2009).

12 Este acordo vai vigorar de 1937 a 1963. Apesar das resoluções aprovadas pelos congressos sindicais a favor de uma indemnização por doença profissional, não vai haver grandes exigências nesse sentido até à catástrofe de Marcinelle em $1956(262$ mortos, dos quais 136 italianos). A questão volta, então, a ser discutida no âmbito da contratação coletiva (na Comissão Nacional Mista do Sector Mineiro) ; os sindicatos atêm-se, então, ao essencial do acordo de 1937. De facto, esse acordo facilita o direito a uma indemnização por via da noção de "incapacidade de trabalhar no subsolo e na superfície", sem qualquer referência a uma patologia específica nem ao grau de invalidez. Nesta medida, não implica pesados processos de avaliação e raramente dá origem a grandes contenciosos. Na ausência de qualquer menção ao grau de invalidez, o mineiro inválido tem direito à pensão por inteiro, calculada nos mesmos moldes do regime geral de pensões (Geerkens, 2014).

13 Depois do desastre de Marcinelle, um conjunto de fatores - a luta dos dois maiores sindicatos pela indemnização da silicose, a perspetiva de encerramentos maciços de minas que ameaçam deixar desamparados mineiros doentes sem direito a 
indemnização por insuficiência de tempo de trabalho no subsolo, nos termos da lei de 1937 - vai levar a uma redução do tempo de exposição que passa de 10 para 5 anos.

Posteriormente, vão entrar em ação as organizações dos mineiros italianos, apoiados, por um lado, pelo seu governo (a lei Bitossi que indemniza os mineiros italianos doentes que regressam a Itália) e, por outro, pelas forças progressistas belgas e ainda a integração económica europeia pela via da CECA e da CEE (segurança social dos trabalhadores migrantes) para, finalmente, se chegar, em 1963, à revisão do regime das doenças profissionais.

\section{As características gerais da Lei de 24 de dezembro de 1963}

15 A revisão concomitante da lei de 1927 e da indemnização da silicose demorou muito a concluir-se, e só dificilmente as organizações sindicais e os seus intermediários políticos conseguiram contrariar os vários meios e estratégias dilatórias do patronato. Essa lentidão deveu-se muito à importância vital do carvão como principal fonte de energia industrial e doméstica até ao início da década de 1960.

16 A lei aprovada em dezembro de 1963 vai dar origem a uma dupla reforma : por um lado, a integração das doenças profissionais no regime geral da segurança social e o financiamento do novo Fundo de Doenças Profissionais por meio de uma contribuição paga por todas as entidades patronais ; por outro, a inclusão da silicose dos mineiros na lista das doenças profissionais. Esta inclusão só foi conseguida na condição de o Estado se comprometer a suportar $50 \%$ dos custos das indemnizações, comparticipação que será aumentada para $65 \%$ em 1970. É, portanto, toda a sociedade que vai suportar os custos para a saúde de uma atividade que está nas mãos do sector privado, visto que, na Bélgica, as minas de carvão nunca foram nacionalizadas. As indemnizações da silicose representam $87,5 \%$ do total das indemnizações pagas durante os primeiros vinte e cinco anos de funcionamento do novo Fundo de Doenças Profissionais, e constituíram a principal atividade deste organismo (Ugeux, 1995, p. 12).

\section{BIBLIOGRAFIA}

Geerkens, E. (2009). Quand la silicose n'était pas une maladie professionnelle. Genèse de la réparation des pathologies respiratoires des mineurs en Belgique (1927-1940). Revue d'histoire moderne et contemporaine, 56(1), 127-141. https://doi.org/10.3917/rhmc.561.0127

Geerkens, E. (2014). La négociation collective d'une maladie professionnelle : la pneumoconiose des ouvriers mineurs en Belgique (c. 1937- c. 1970). In J. Rainhorn (Dir.), Santé et travail à la mine, XIX-XXIe siècles (pp. 59-79). Villeneuve d'Ascq : Presses Universitaires du Septentrion.

Moldaver, J. (1939). Le problème social des maladies professionnelles et sa solution en droit belge. Bruxelles : Falk. 
Ugeux, J. (1995). L'assurance contre les maladies professionnelles. In Ministère de la prévoyance sociale : Cinquante ans de sécurité sociale... et après ? vol. 5 :Quand le travail nuit à la santé (pp. 11-42). Bruxelles : Bruylant.

\section{NOTAS}

1. Convenção OIT no 42, relativa às doenças profissionais (modificada em 1934), que entrou em vigor a 17 de junho de 1936.

\section{AUTOR}

\section{ERIC GEERKENS}

Département des sciences historiques. Faculté de Philosophie et Lettres. Université de Liège. Quai Roosevelt, 1B (bât A4) - 4000 Liège, Belgique

E.Geerkens@uliege.be 